\title{
PENGARUH KOMUNIKASI EFEKTIF UNTUK MENINGKATKAN HASIL BELAJAR MAHASISWA
}

\author{
Hugo Aries Suprapto \\ Program Studi Teknik Industri \\ Fakultas Teknik Matematika dan Ilmu Pengetahuan Alam \\ Universitas Indraprasta PGRI Jakarta
}

\begin{abstract}
With effective communication, the managerial functions that originated from the functions, implementation and monitoring can be achieved. This study used an experimental method. Subjects were students of the seventh semester of Industrial Engineering as many as 25. There is a significant influence effective communication to increase student learning outcomes. The data was processed with SPSS 22. The results showed, normality test, homogeneity and T Samples Paired with a significant level of $\alpha$ $=5 \%$, the normality test results obtained prior to the effective communication Kolmogorof-Smirnov value Sig. 0190, and Shapiro-Wilk 0215 so that at $\alpha=5 \%=0: 05$ $<$ Sig. $=0$, the sample data came from a normal distribution. While the test results of normality after the effective communication of values obtained Kolmogorof-Smirnov Sig. 0134 , and Shapiro-Wilk 0346 so that at $\alpha=5 \%=0: 05<$ Sig. $=0$, the sample data came from a normal distribution. At Variance Homogeneity Test Levene Value Sig. 0096, at a significance level of $\alpha=5 \%=0: 05<$ Sig.0.096 so that it can be said of data samples derived from the variances are homogenous, it can be concluded on a confidence level of 95\%, on average after the effective communication to improve student results mean for entrepreneurship courses 80.9600) compared to before using effective communication (mean of 64.7200), rose by 16:24. In other words, the use of effective communication wear a significant effect on improving learning outcomes 95\%. This study gives suggestions to overcome the problems found in the study.
\end{abstract}

Keywords: effective communication, learning outcomes

\begin{abstract}
Abstrak
Melalui komunikasi yang efektif, maka fungsi manajerial yang berawal dari fungsi, implementasi dan pengawasan dapat dicapai. Penelitian ini memakai metode eksperimen. Subyek penelitian adalah mahasiswa Teknik Industri semester tujuh sebanyak 25. Terdapat pengaruh yang signifikan komunikasi efektif terhadap peningkatan hasil belajar mahasiswa. Data diolah dengan SPSS 22. Hasil penelitian
\end{abstract}


Hugo Aries Suprapto : Pengaruh Komunikasi Efektif untuk Meningkatkan Hasil Belajar Mahasiswa

menunjukkan pada, Uji Normalitas, Homogenitas dan T Sampel Berpasangan dengan tingkat signifikan $\alpha=5 \%$, Hasil uji normalitas sebelum kmunikasi efektif didapat nilai Kolmogorof-Smirnov Sig. 0.190, dan Shapiro-Wilk 0.215 sehingga pada $\alpha=5 \%=0.05$ $<$ Sig.= 0, sampel data berasal dari distribusi normal. Sedangkan Hasil uji normalitas sesudah komunikasi efektif didapat nilai Kolmogorof-Smirnov Sig. 0.134, dan Shapiro-Wilk 0.346 sehingga pada $\alpha=5 \%=0.05<$ Sig. $=0$, sampel data berasal dari distribusi normal. Pada Uji Homogenitas Varians Levene Nilai Sig. 0.096, pada tingkat signifikansi $\alpha=5 \%=0.05<$ Sig. 0.096 sehingga dapat dikatakan sampel data berasal dari varians yang Homogen, dapat disimpulkan pada tingkat kepercayaan 95\%, ratarata sesudah komunikasi efektif untuk meningkatkan hasil belajar mahasiswa mata kuliah kewirausahaan mean sebesar 80.9600 ) dibanding sebelum memakai komunikasi efektif (mean sebesar 64.7200), naik sebesar 16.24. Dengan kata lain, penggunaan memakai komunikasi efektif berpengaruh signifikan pada peningkatan hasil belajar 95\%. Penelitian ini memberikan saran untuk mengatasi masalah yang ditemukan dalam penelitian.

Kata kunci: komunikasi efektif, hasil belajar

\section{PENDAHULUAN}

Pada saat ini masih banyak didapati di berbagai institusi pendidikan, pelatihan, termasuk perguruan tinggi, yang dalam mengajar masih konvensional. Pengajar baik guru/dosen mengajar secara ilmiah sesuai dengan bakat mengajar yang dimiliki. Ada juga guru/dosen yang dalam mengajar cenderung meniru gaya orang yang dahulu, sehingga akan menimbulkan persoalan, baik bagi pengajar maupun peserta didik. Tipe pertama misalnya, akan menimbulkan masalah bagi dosen yang tidak memiliki bakat mengajar atau mempunyai keterbatasan dalam menyampaikan pesan secara lisan, adapun untuk tipe kedua, jika tidak hati-hati, dosen cenderung akan meniru gaya orang yang diidolakannya, tanpa melihat sisi kelemahannya.

Menurut Anderson (1959) komunikasi merupakan suatu proses dimana kita dapat memahami dan dipahami oleh orang lain. Komunikasi merupakan proses yang dinamis dan secara konstan berubah sesuai dengan situasi yang belaku (Syaiful Rohim, 2009: 10).Menurut Moor, komunikasi adalah 
penyampaian pengertian antar individu. Dia mengatakan semua manusia dilandasi kapasitas untuk menyampaikan maksud, hasrat, perasaan, pengetahuan dan pengalaman dari orang yang satu kepada orang yang lain. Pada pokoknya komunikasi adalah pusat minat dan situasi perilaku dimana suatu sumber menyampaikan pesan kepada seorang penerima dengan berupaya mempengaruhi perilaku penerima tersebut (Syaiful Rohim, 2009: 8).Metode adalah cara yang dapat digunakan untuk melaksanakan strategi. Pemilihan metode pembelajaran dapat disesuaikan dengan materi yang hendak disampaikan, kemampuan dosen dalam mengelola sumber belajar, waktu yang tersedia, dan sarana/prasarana yang tersedia. (Marsudi Wahyu Kisworo: 121).

Komunikasi merupakan seni penyampaian informasi (pesan, ide, sikap, atau gagasan) dari komunikator atau penyampaian berita, untuk mengubah serta membentuk perilaku komunikasi atau penerima berita (pola, sikap, pandangan, dan pemahamannya), kelola dan pemahaman yang dikehendaki bersama. Komunikasi harus dilakukan secara efektif agar komunikasi itu dapat mudah dimengerti oleh komunikan, komunikasi yang efektif dapat dilakukan apabila seseorang yang berkomunikasi memahami tentang pengertian dari komunikasi efektif, proses komunikasi efektif dan unsur-unsur komunikasi efektif.

Komunikasi merupakan sarana untuk terjalinnya hubungan antar seseorang dengan orang lain, dengan adanya komunikasi maka terjadilah hubungan sosial, karena bahwa manusia itu adalah sebagai makhluk sosial, antara yang satu dengan yang lainnya saling membutuhkan, sehingga terjadinya interaksi yang timbal balik. Dalam hubungan seseorang dengan orang lain tentunya terjadinya proses komunikasi itu tentunya tidak terlepas dari tujuan yang menjadi topik atau pokok pembahasan, dan juga untuk tercapainya proses penyampaian informasi itu akan berhasil apabila ditunjang dengan alat atau media sebagai sarana penyaluran informasi atau berita. 
Hugo Aries Suprapto : Pengaruh Komunikasi Efektif untuk Meningkatkan Hasil Belajar Mahasiswa

Dalam kenyataannya bahwa proses komunikasi itu tidak selalu lancar, hal itu terjadi dikarenakan kurangnya memperhatikan unsur-unsur yang mestinya ada dalam proses komunikasi. Dari uraian tersebut, bahwa dalam komunikasi itu perlu diperhatikan mengenai unsur-unsur yang berkaitan dengan proses komunikasi, baik itu oleh komunikator maupun oleh komunikan, dan juga bahwa komunikator harus memahami dari tujuan komunikasi.

Upaya peningkatan prestasi belajar siswa tidak terlepas dari berbagai faktor yang mempengaruhinya. Dalam hal ini, diperlukan guru kreatif yang dapat membuat pembelajaran menjadi lebih menarik dan disukai oleh peserta didik. Suasana kelas perlu direncanakan dan dibangun sedemikian rupa dengan menggunakan model pembelajaran yang tepat agar siswa dapat memperoleh kesempatan untuk berinteraksi satu sama lain sehingga pada gilirannya dapat diperoleh prestasi belajar yang optimal. Oleh karena itu, penulis akan menguraikan materi tentang Komunikasi dalam Proses Manajemen Pendidikan agar kita dapat melakukan komunikasi yang efektif.

Menurut Kamus Besar Bahasa Indonesia (KBBI), komunikasi diartikan sebagai pengiriman dan penerimaan pesan atau berita antara dua orang atau lebih sehingga pesan yang dimaksud dapat dipahami, hubungan, kontak. Komunikasi berasal dari kata latin cum yaitu kata depan yang berarti dengan, bersama dengan, dan unus yaitu kata bilangan yang berarti satu. Dari kedua kata itu terbentuk kata benda communio yang dalam bahasa Inggris menjadi communion dan berarti kebersamaan, persatuan, persekutuan, gabungan, pergaulan, dan hubungan. Komunikasi adalah suatu pemindahan makna atau pemahaman dari pengirim kepada penerima, di dalamnya tercangkup tiga bagian penting dari komunikasi yang efektif yakni sang pengirim, sang penerima dan keberhasilan pengirim makna. 
Komunikasi adalah proses berbagi makna melalui perilaku verbal dan non verbal. Segala perilaku dapat disebut komunikasi jika melibatkan dua orang atau lebih. Frase dua atau lebih perlu ditekankan,karena sebagian literatur menyebut istilah komunikasi intrapersonal, yakni komunikasi diri sendiri. Komunikasi terjadi jika setidaknya suatu sumber membangkitkan respons pada penerima melalui penyampaian suatu pesan dalam bentuk tanda atau simbol,baik bentuk verbal atau bentuk nonverbal,tanpa harus memastikan terlebih dulu bahwa kedua pihak yang berkomunikasi punya suatu sistemsimbol yang sama. Komunikasi efektif terjadi apabila sesuatu (pesan) yang diberitahukan komunikator dapat diterima dengan baik atau sama oleh komunikan,sehingga tidak terjadi salah persepsi.

Komunikasi efektif adalah komunikasi yang mampu untuk menghasilkan perubahan sikap pada orang yang terlihat dalam komunikasi. Tujuan komunikasi efektif adalah memberi kemudahan dalam memahami pesan yang disampaikan antara pemberi dan penerima sehingga bahasa lebih jelas, lengkap, pengiriman dan umpan balik seimbang, dan melatih menggunakan bahasa non verbal secara baik. Menurut Jalaluddin dalam bukunya Psikologi Komunikasi (2008:13) menyebutkan, komunikasi yang efektif ditandai dengan adanya pengertian, dapat menimbulkan kesenangan, mempengaruhi sikap, meningkatkan hubungan sosial yang baik, dan pada akhirnya menimbulkan suatu tindakan.

Komunikasi dikatakan efektif dalam pembelajaran apabila terdapat aliran informasi dua arah antara pendidik dengan peserta didik dan informasi tersebut sama-sama direspon sesuai dengan harapan kedua pelaku komunikasi tersebut(Abdul Majid, 2013). Meskipun penelitian mereka terfokus pada komunikasi efektif untuk proses belajar-mengajar, hal yang dapat dimengerti di sini adalah bahwa suatu proses komunikasi membutuhkan aktivitas, cara dan 
Hugo Aries Suprapto : Pengaruh Komunikasi Efektif untuk Meningkatkan Hasil Belajar Mahasiswa

sarana lain agar bisa berlangsung dan mencapai hasil yang efektif.William J. Seiler (1988) memberikan definisi komunikasi yang lebih bersifat universal. Dia mengatakan komunikasi adalah proses dengan mana simbol verbal dan nonverbal dikirimkan, diterima dan diberi arti (Arni Muhammad, 2011: 4).

\section{METODE PENELITIAN}

Metode penelitian yang digunakan adalah metode eksperimen. Populasi studi adalah semua mahasiswa Teknik Industri semester tujuh Universitas Indraprasta PGRI Jakarta, dengan menggunakan teknik Random Sampling. Populasi penelitian sebanyak 25 mahasiswa. Responden dalam penelitian ini adalah mahasiswa Teknik Industri sebanyak 25 mahasiswa semester ganjil tahun ajaran 2016/2017. Waktu penelitian pada bulan September sampai dengan November 2016. Tujuan penelitian untuk mengetahui (1). Pengaruh komunikasi efektif terhadap hasil belajar mahasiswa. Penelitian ini memakai rancangan eksperimen yang dilakukan pada satu kelompok saja tanpa kelompok pembanding (The One Group Pratest Posttest). Model ini lebih sempurna karena sudah menggunakan tes awal (pratest) kemudian setelah diberikan perlakukan dilakukan pengukuran (post test) untuk mengetahui akibat dari perlakuan (treatment), sehingga besarnya efek dari eksperimen dapat diketahui dengan pasti. Instrumen yang diberikan berupa pertanyaan seputar dunia bisnis (kewirausahaan), (Tema: menumbuhkan minat wirausaha dibidang consumer good dan jasa), baik sebelum dan sesudah dilakukan perlakukan (treatment) pemakaian komunikasi efektif. Data dilakukan Uji Normalitas dan Homogenitas serta memakai Uji-t (One Sample t Test). Penghitungan memakai SPSS 22.Skemadari model penelitian adalah: 
Tabel 1. SkemaRancanganPenelitian

\begin{tabular}{|c|c|c|}
\hline $\mathrm{T} 1$ & $\mathrm{X}$ & $\mathrm{T} 2$ \\
\hline Pretest & Treatment & Posttest \\
\hline
\end{tabular}

Keterangan :

$\mathrm{T}_{1}$ : Tesawal yang diberikan pada kelas eksperimen di awalpenelitian

$\mathrm{X}$ : Perlakuan yang diberikan pada kelas eksperimen: memakai komunikasi efektif

$\mathrm{T}_{2}$ : Tesakhir yang diberikanpadakelaseksperimen di akhirpenelitian

\section{HASIL DAN PEMBAHASAN}

Pengaruh komunikasi efektif untuk meningkatkan hasil belajar belajar mahasiswa merupakan salah satu model pembelajaran inovatif. Komunikasi efektif berfokus pada konsep dan prinsip inti sebuah disiplin, memfasilitasi mahasiswa untuk berinvestigasi, pemecahan masalah, dan tugas-tugas bermakna lainnya, student centered, dan menghasilkan produk nyata. 1). Dalam Pembelajaran kewirausahaan menggnakan komunikasi efektif, projek dilakukan secara kolaboratif dan inovatif, unik, berfokus pada pemecahan masalah yang berhubungan dengan kehidupan mahasiswa atau kebutuhan masyarakat atau industri lokal. Pada pembelajaran berbasis kewirausahaan dalam penelitian ini, projek dirancang yang terkait dengan penumbuhan nilai-nilai kewirausahaan. Kelebihan komunikasi efektif untuk meningkatkan hasil belajar mata kuliah kewirausahaan ini adalah dapat membuat pengalaman belajar menjadi lebih menarik dan bermakna bagi mahasiswa. Dalam mata kuliah kewirausahaan ini, mahasiswa menjadi terdorong lebih aktif dalam belajar, dosen hanya sebagai fasilitator, dosen mengevaluasi produk hasil kinerja mahasiswa yang meliputi outcome yang mampu ditampilkan dari hasil proyek yang dikerjakan. 
Hugo Aries Suprapto : Pengaruh Komunikasi Efektif untuk Meningkatkan Hasil Belajar Mahasiswa

Pengolahan pada SPSS 22 dapat dilihat pada tabel 2 dibawah ini:

Tests of Normality

\begin{tabular}{|r|l|r|r|r|r|r|r|}
\hline \multirow{2}{*}{$\begin{array}{l}\text { ah } \\
\text { ahelum_dan_Sesud }\end{array}$} & \multicolumn{3}{|c|}{ Kolmogorov-Smirnov ${ }^{\text {a }}$} & \multicolumn{3}{|c|}{ Shapiro-Wilk } \\
\cline { 2 - 8 } & Statistic & \multicolumn{1}{c|}{ df } & Sig. & Statistic & \multicolumn{1}{c|}{ df } & \multicolumn{1}{c|}{ Sig. } \\
\hline \multirow{2}{*}{ Nilai } & 1,00 &, 144 & 25 &, 190 &, 947 & 25 &, 215 \\
& 2,00 &, 153 & 25 &, 134 &, 956 & 25 &, 346 \\
\hline
\end{tabular}

a. Lilliefors Significance Correction

Sumber data yang telah diolah

Pada tingkat signifikansi $\alpha=5 \%$, kolom Kolmogorov-Smirnov (KS) terlihat sebelum diberikan komunikasi yang efektif signifikansi pada tabel. 2,karena $\alpha=$ $5 \%=0.05<$ Sig. $=0.190$, sesudah diberikan komunikasi efektif $\alpha=$ $5 \%=0.05<$ Sig. $=0.134$, maka Hotidak ditolak.

Pada tingkat signifikansi $\alpha=5 \%$, kolom Shapiro-Wilk (SW) terlihat sebelum diberikan komunikasi yang efektif signifikansi pada tabel 2 , karena $\alpha=$ $5 \%=0.05<$ Sig. $=0.215$, sesudah diberikan komunikasi yang efektif $\alpha=5 \%=$ $0.05<$ Sig. $=0.346$ maka $\mathrm{H}_{0}$ tidak ditolak.

Dari uji Kolmogorov dan Shapiro-Wilk dapat disimpulkan, karena Hoditerima maka asumsi bahwa sampel data berasal dari distribusi normal.

Tabel3.UjiHomogenitasVariansLevene

Test of Homogeneity of Variances

\begin{tabular}{|c|c|c|c|}
\hline \multicolumn{4}{|c|}{ Nilai } \\
\hline Levene Statistic & df1 & df2 & Sig. \\
\hline 2,886 & 1 & 48 &, 096 \\
\hline
\end{tabular}

Sumber: Data yang telah diolah. 
Tingkat signifikansi $\alpha=5 \%$, pada tabel 3, kolom Sig. Karena $\alpha=5 \%=0.05<$ Sig.0.96, maka Hotidak ditolak, dengan kata lain, asumsi homogenitas varians dapat terpenuhi.

Tabel 4.Statistik Sampel Berpasangan/Sampel T

\section{Paired Samples Statistics}

\begin{tabular}{|cc|c|c|c|c|}
\hline & & Mean & N & Std. Deviation & Std. Error Mean \\
\hline \multirow{2}{*}{ Pair 1 } & Sebelum & 64,7200 & 25 & 7,18517 & 1,43703 \\
& Sesudah & 80,9600 & 25 & 5,26371 & 1,05274 \\
\hline
\end{tabular}

Pada tabel 4, diatas tertera rata-rata nilai sebelum pemakaian media sebesar 64.7200 dengan standard deviasi sebesar 7.18517, sedangkan nilai sesudah pemakaian media sebesar 80.9600 dengan standard deviasi sebesar 5.26371.

Tabel 5. Uji T SampelBerpasangan

Paired Samples Test

\begin{tabular}{|c|c|c|c|c|c|c|c|c|c|}
\hline & & \multicolumn{5}{|c|}{ Paired Differences } & \multirow{3}{*}{$t$} & \multirow{3}{*}{$d f$} & \multirow{3}{*}{$\begin{array}{l}\text { Sig. (2- } \\
\text { tailed) }\end{array}$} \\
\hline & & \multirow[t]{2}{*}{ Mean } & \multirow[t]{2}{*}{$\begin{array}{c}\text { Std. } \\
\text { Deviation }\end{array}$} & \multirow[t]{2}{*}{$\begin{array}{l}\text { Std. Error } \\
\text { Mean }\end{array}$} & \multicolumn{2}{|c|}{$\begin{array}{c}95 \% \text { Confidence Interval } \\
\text { of the Difference }\end{array}$} & & & \\
\hline & & & & & Lower & Upper & & & \\
\hline Pair 1 & $\begin{array}{l}\text { Sebelum - } \\
\text { Sesudah }\end{array}$ & $-16,24000$ & 7,07272 & 1,41454 & $-19,15947$ & $-13,32053$ & $-11,481$ & 24 & ,000 \\
\hline
\end{tabular}

Berdasarkan hasil tabel 5, Uji T Sampel Berpasangan dengan tingkat signifikan $\alpha=5 \%$, pada tabel. 5, kolom $\mathrm{t}$ dan $\mathrm{df}$, diperoleh $\mathrm{t}=-11.481$ dan $\mathrm{df}=24$. Dari tabel $\mathrm{t}$ diperoleh nilai $\mathrm{t} 0.05 ; 24=1.708$. Karena $\mathrm{t}=-11.481<-\mathrm{t} 0.05 ; 24=-.708$, maka Ho ditolak. Pada kolom Sig. (2-tailed) tabel Uji T Sampel ,karena 
digunakanhipotesis satu sisi ( $\mathrm{H} 1: \mu 1-\mu_{2}<0$ atau $\mathrm{H}_{1}: \mu_{1}<\mu_{2}$, maka $0.000: 2$ $=0$, maka $0.05>$ Sig. $=0$, maka Hoditolak.

Pengambilan keputusan dengan cara diatas dapat diperoleh hasil yang sama yakni Hoditolak. Hal tersebut dapat disimpulkan pada tingka kepercayaan 95\%, rata-rata sebelum pemakaian komunikasi efektif setelah perlakuan dengan setelah memakai komunikasi efektif (mean sebesar 80.9600) dibanding sebelum memakai komunikasi efektif (mean sebesar 64.7200), naik sebesar 16.24. Dengan kata lain, pemakaian komunikasi efektif berpengaruh signifikan pada tingkat kepercayaan $95 \%$.

\section{KESIMPULAN}

Data yang sudah diolah berdistribusi normal begitu pula dengan uji homogenitas Varians Levene, data bervarian homogen. Berdasarkan pembahasan di atas dapat disimpulkan sebagai berikut :1). Pemakaian komunikasi efektif sangat berpengaruh pada peningkatan hasil belajar mahasiswa Teknik Industri semester tujuh, 2). Pemakaian komunikasi efektif berpengaruh signifikan pada penguasaan mata kuliah Kewirausahaan. Setelah pemakaian komunikasi yang efektif, ada kenaikan sebesar 16.24.

Membangun suasana pembelajaran yang diiringi pujian dosen terhadap hasil karya mahasiswa, disertai pertanyaan dosen yang menantang, serta dorongan agar mahasiswa melakukan percobaan menjadi amat penting bagi dosen. Pengaruh komunikasi yang efektif dan tepat dan bervariasi sangat berperan pada peningkatan hasil belajar mahasiswa. Mahasiswa lebih antusias dan termotivasi untuk mengungkapkan kata-kata dan kalimat. Penggunaan komunikasi efektif menjadi media yang menarik dan dapat meningkatkan 
penguasaan materi kewirausahaan. Dosen di bidang mata kuliah kewirausahaan harus selalu menampilkan metode pembelajaran yang inovasi.

Memuji kreativitas mahasiswa harus disesuaikan dengan karakter dan sifatnya. Kadang, ada mahasiswa yang tidak suka dipuji terlalu lama atau bahkan dipamerkan dan kadang ada pula mahasiswa kalau dipuji motivasi belajarnya akan kian terpacu. Pembelajaran dengan menggunakan komunikasi yang efektif dapat menjadi alat yang baik yang dapat dipakai di Perguruan Tinggi, terutama mahasiswa Teknik Industri semester tujuh yang sedang belajar ilmu kewirausahaan. Dosen yang dapat mengubah suasana kelas menjadi aktif dan menarik, pasti akan membuat mahasiswa termotivasi untuk belajar tanpa paksaan dan beban.

Pemakaian media komunikasi yang efektif ini tidak hanya di Perguruan Tinggi saja melainkan di rumah, sebab dapat membantu mempercepat penguasaan mata kuliah kewirausahaan. Mahasiswa akan mengeluarkan ide-ide dan pemikirannya secara bebas sehingga melatih keterampilan kewirausahaan dengan menggunakan bahasa untuk berkomunikasi.

\section{DAFTAR PUSTAKA}

Abdul Majid. 2013. Strategi Pembelajaran. Bandung: Remaja Rosdakarya. Arni Muhammad. 2011. Komunikasi Organisasi. Jakarta: Bumi Aksara. Jalaludin Rakhmat. 2008. Psikologi Komunikasi, edisi revisi. Bandung: Remaja Rosdakarya.

Marsudi Wahyu Kisworo. (2016). Revolusi Mengajar. Pembelajaran Aktif, Kreatif, Efektif, Menyenangkan (Pakem). Jakarta: Asik Generation.

Pramesti Getut. 2014. Kupas Tuntas Data Penelitan dengan SPSS 22 cetakan ketiga. Jakarta: PT Elek Media Komputindo. 
Hugo Aries Suprapto : Pengaruh Komunikasi Efektif untuk Meningkatkan Hasil Belajar Mahasiswa

Santoso Singgih. 2015. SPSS 20 Pengolah Data Statistik di Era Infomasi. Jakarta: PT Elek Media Komputindo.

Sugiyono. 2010. Metode Penelitian Pendidikan Pendekatan Kuantitatif, Kualitatif, dan R\&D.Cetakan ke 10. Bandung: Alfabeta.

Suparman. 2014. Aplikasi Komputer Dalam Penyusunan Karya Ilmiah. Cetakan ke. 3. Tangerang: Pustaka Mandiri.

Syaiful Rohim. 2009. Teori Komunikasi Perspektif Ragam Dan Aplikasi. Jakarta: Rineka Cipta. 